\title{
Perspectives on the emergence of diatoms and their impact on the global biogeochemical cycle of silica
}

DANIEL J. CONLEY ${ }^{1}$, KAROLINA BRYLKA ${ }^{1}$, SYLVAIN RICHOZ $^{1}$ AND ANDREW ALVERSON ${ }^{2}$

${ }^{1}$ Lund University

${ }^{2}$ University of Arkansas

Presenting Author: daniel.conley@geol.lu.se

The lack of diatoms in the fossil record has skewed our understanding of the evolution of diatoms and their impact on the global biogeochemical cycle of silica. As has occurred with most fossils the older evidence for diatoms has likely been destroyed during diagenesis, subducted or is concealed deep within the Earth. To date most studies have focused on diversification during the mid-Cenozoic, $30 \mathrm{Ma}$ ago, where abundant diatom fossils are found with their expansion related to a significant enhancement of weathering and dissolved Si flux to the oceans.

Molecular clocks suggest that diatoms evolved over $200 \mathrm{Ma}$ ago, although this result has been largely ignored because of the lack of diatoms in the geologic fossil record. Therefore, we are searching for evidence of the emergence of diatoms and speciation in the geological record by examining formations in which diatoms are likely to have previously accumulated in ocean sediments. We are also investigating the timing and magnitude of dissolved $\mathrm{Si}$ drawdown in the oceans following the origin of diatoms using the isotopic silicon composition of fossil sponge spicules and radiolarians. The project will provide new insights into the timing of dissolved Si drawdown and other key events, which reorganized the distribution of carbon and nutrients in seawater, changing energy flows and productivity in the biological communities of the ancient oceans. 